\title{
2006-2565: THE VERTICALLY-INTEGRATED PROJECTS (VIP) PROGRAM IN ECE AT PURDUE: FULLY INTEGRATING UNDERGRADUATE EDUCATION AND GRADUATE RESEARCH
}

\section{Edward Coyle, Purdue University}

Edward J. Coyle received his BSEE degree from the University of Delaware in 1978, and Master's and Ph.D. degrees in Electrical Engineering and Computer Science from Princeton University in 1980 and 1982. Since 1982, he has been with Purdue University, where he is currently Professor of Electrical and Computer Engineering, Co-Director of the Center for Wireless Systems and Applications (CWSA), and Director of the EPICS Entrepreneurship Initiative (EEI). From 2000 through 2004 he served Purdue as Assistant Vice Provost for Research in Computing and Communications.

His research interests include the performance analysis of computer and sensor networks, signal and image processing, and engineering education. He was a co-recipient of both the Myril B. Reed Best Paper Award from the 32nd Midwest Symposium on Circuits and Systems and the 1986 Best Paper Award for Authors under 30 from the Signal Processing Society of the IEEE. He has served as an associate editor of the IEEE Transactions on Circuits and Systems and was an elected member of the Board of Governors of the IEEE Circuits and Systems Society. He was the general chair of the 1997 IEEE/EURASIP Workshop on Nonlinear Signal and Image Processing. Dr. Coyle is a Fellow of the IEEE and in 1998 was named an Outstanding Engineering Alumnus of the University of Delaware.

Dr. Coyle was a co-founder, with Professors Leah Jamieson and Hank Dietz, of the Engineering Projects in Community Service (EPICS) Program at Purdue. He was also a co-founder and co-director, with Professors Leah Jamieson and Bill Oakes, of the National EPICS Program, which supports and coordinates EPICS sites at Purdue and 14 other universities. Further information about EPICS is available at http://epics.ecn.purdue.edu/.

For their work with the EPICS Program, Professors Coyle and Jamieson have jointly received the School of Electrical and Computer Engineering's 1997 Ruth and Joel Spira Outstanding Teacher Award, Purdue's Class of 1922 Award for Outstanding Innovation in Helping Students Learn, and the 1997 Chester F. Carlson Award for Innovation in Engineering Education from the American Society for Engineering Education (ASEE). The EPICS Program has been honored with several awards, including the Corporate and Foundation Alliance Award and, from the State of Indiana, the Inaugural Governor's Award for Outstanding Volunteerism. With Professors Jamieson and Oakes, Coyle was a co-recipient of the National Academy of Engineering's 2005 Bernard M. Gordon Prize for Innovation in Engineering and Technology Education.

\section{Jan Allebach, Purdue University}

Jan P. Allebach received his BS degree from the University of Delaware in 1972, and his MS and Ph.D. degrees from Princeton University in 1975 and 1976, respectively, all in electrical engineering. From 1972 to 1975, he was a National Science Foundation Graduate Fellow. He was with the Department of Electrical Engineering at the University of Delaware from 1976 to 1983. Since 1983, he has been with the School of Electrical and Computer Engineering at Purdue University, where he holds the rank of Professor. Professor Allebach's research has primarily been in the areas of printing and display of images, scanning and sampling of multidimensional signals, and synthesis of digital diffractive elements. He has been a visiting summer faculty member at IBM Watson Research Center in Yorktown Heights, NY, Sandia Labs in Livermore, CA, and Hewlett-Packard Labs in Palo Alto, CA. In addition, he has consulted extensively for industry and government laboratories.

Professor Allebach is a Fellow of the IEEE, a Fellow of the Society for Imaging Science and Technology (IS\&T), and a member of the Optical Society of America. In 1987, he received the 
Senior Award from the IEEE Signal Processing Society for his paper on time-sequential sampling published in the February 1984 issue of the IEEE Transactions on Signal Processing. During 1991-1992, he served as the IS\&T Visiting Lecturer. During 1994-1995, he was a Distinguished Lecturer for the IEEE Signal Processing Society. Professor Allebach received an Outstanding Engineering Alumni Award from the University of Delaware in 1996. In 1998, he received the IS\&T Raymond C. Bowman Award. He has also received two teaching awards at Purdue University.

Professor Allebach served on the Image and Multidimensional Signal Processing (IMDSP) Technical Committee of the IEEE Signal Processing Society from 1986 to 1995, and chaired it from 1991 to 1992. Professor Allebach served as Secretary of the IEEE Signal Processing Society from 1992 to 1995. He served as an elected member of the IEEE Signal Processing Society Board of Governors from 1996 to 1998 . He served as Chapters Vice-President of IS\&T from 1992 to 1996. Professor Allebach is a past Associate Editor for the IEEE Transactions on Signal Processing and the IEEE Transactions on Image Processing. He is currently Editor of the IS\&T/SPIE Journal of Electronic Imaging. Professor Allebach was Co-Technical Chair of ICASSP-93 held in Minneapolis, MN, Co-General Chair of the 9th IMDSP Workshop held in Belize City, Belize in March 1996, and Co-General Chair of EI-99 held in San Jose in February 1999.

\section{Joy Krueger, Purdue University}

Joy Garton Krueger serves as Visiting Assistant Professor within the Purdue University College of Engineering, Department of Engineering Projects in Community Services (EPICS). Initially prepared at the undergraduate level as a science and mathematics educator in 1981, Dr. Krueger expanded her professional interests in educational and organizational assessment and evaluation, instructional research and development, and adult learning by obtaining Master's and Ph.D. degrees from Purdue's College of Education in 1987 and 1991.

Since 1990, Dr. Krueger has held leadership roles as Purdue University Registrar, Senior Policy Analyst, and Assistant Dean in the College of Education. These positions enabled Krueger to serve the university and college during critical times of major organizational change resulting in improved student data systems, relevant academic policies, outcomes based curricula, effective programmatic assessment and evaluation strategies, and national and state accreditation. Additionally, Dr. Krueger has owned three companies and currently guides other professionals pursuing entrepreneurship endeavors in both the private and public sectors via her current endeavor Pathways to Performance, Inc.

Dr. Krueger's research interests include educational and organizational assessment and evaluation, teaching and learning engineering within $\mathrm{P} / \mathrm{K}-16$ and its application to the college curricula and academic performance standards as a means for developing quality diverse engineers and entrepreneurs; and the role of multidisciplinary faculty within engineering education. 


\title{
The Vertically-Integrated Projects (VIP) Program in ECE at Purdue: Fully Integrating Undergraduate Education and Graduate Research
}

\begin{abstract}
The Vertically-Integrated Projects (VIP) Program is an engineering education program that operates in a research and development context. Undergraduate students that join VIP teams earn academic credit for their participation in design efforts that assist faculty and graduate students with research and development issues in their areas of technical expertise. The teams are: multidisciplinary - drawing students from across engineering; vertically-integrated maintaining a mix of sophomores through $\mathrm{PhD}$ students each semester; and long-term - each undergraduate student may participate in a project for up to seven semesters and each graduate student may participate for the duration of their graduate career. The continuity, technical depth, and disciplinary breadth of these teams enable the completion of projects of significant benefit to faculty members' research programs.
\end{abstract}

\section{Introduction}

Sustaining and accelerating the rapid pace of innovation in electrical and computer engineering will require a continuous stream of new graduates that have been educated and trained to understand how the processes of research, technology advancement, and applications development should be integrated to enable innovations. Current approaches to the education of undergraduates and graduate students are not up to this challenge: undergraduates are generally not provided with a deep exposure to any technology area; Master's students are often not involved in research or the development of new technology; and PhD students rarely see their breakthroughs implemented and tested in applications.

We have thus developed a new curriculum that integrates education and research in Electrical and Computer Engineering: the Vertically-Integrated Projects (VIP) Program ${ }^{1}$. It demonstrates that research and education can be integrated to better educate engineering students at all levels and to solve real-world problems. The VIP program creates and supports teams of faculty, graduate students, and undergraduate students that work together on long-term, large-scale projects. The focus of each project team is on challenges in research, development, and applications that are of interest to federal funding agencies, industry, and not-for-profit organizations.

The design of the VIP program has directly borrowed the large, vertically-integrated team structure of the EPICS program ${ }^{2}$. This team structure is a proven vehicle for the completion of long-term, large-scale design projects by undergraduates. The VIP program departs from EPICS, however, by adding graduate students to the teams and focusing the design project on research and development projects defined by faculty. This research focus of these projects provides several advantages:

- It engages faculty in the project at a very high level because the activities of the team directly support the faculty member's research effort - including the generation of publications and prototypes. These projects thus maintain the long-term engagement and 
commitment of faculty, including the generation of research proposals to continue funding of the faculty member's project team.

- It engages graduate students in the mentoring of undergraduate students that are assisting them with their research efforts. This will accelerate the graduate students' research effort and enable the undergraduates to learn directly about the goals and responsibilities of graduate students. We expect that, when compared with students not enrolled in the VIP program, those that in VIP will be more likely to attend graduate school.

- It expands the scope of possible projects to include any discipline in which faculty are pursuing research. Our initial effort in the VIP area is focused on engineering and computer science, but the notion of undergraduates directly participating in and benefiting from research efforts extends, with appropriate adaptation, to any academic discipline.

- It provides opportunities for the integration of the research and education enterprises within the university. It creates a community including undergraduates, graduate students, and faculty that work together to attain technical goals. This experiential component for the undergraduates gives them great insight into their field of study, all the way up to the research questions that are posed by faculty. It also provides long-term contact between all members of the VIP team, thus leading to a much more collegial approach to education and the opportunity for long-term mentoring.

This paper is organized as follows. In Section 2, we describe the team structure and the roles of each level of team member. In Section 3, we provide a detailed example of an existing VIP team, including the projects it has delivered. Section 4 summarizes the results of evaluations from the first semester of the program. Additional teams that have been proposed by faculty for 2006 are described in the Appendix.

\section{VIP Team and Curricular Structure}

The curricular infrastructure is in place and four VIP teams are underway: e-Stadium, Wireless Transportation, Multimedia Applications, and Digital Publishing. Three additional VIP teams will be launched in 2006: Sensor Networks, Galileo, and Wireless Propagation.

\section{VIP Team Structure and Operation:}

Leadership: Engineering faculty members lead and are responsible for the success of the project team. The project topic typically falls within the faculty member's research interests. This ensures the engagement of faculty in the project because the team contributes to the advancement of the faculty member's research agenda, including the design and execution of experiments, the implementation of ideas, and the generation of research publications

Focus: Engineering projects that are of interest to the faculty members and the projects' partners. The projects may be from any field of engineering but are currently concentrated in electrical and computer engineering. Two of the current projects are multidisciplinary: the wireless transportation team is supervised by two faculty, one from ECE and one from CE; the Galileo team is supervised by one faculty member from ECE and one from Aero. As other departments 
throughout the College of Engineering implement the VIP course sequence, there will be opportunities for students from any discipline to join a team.

\section{Team Members and Their Responsibilities:}

- The faculty members providing team leadership (1 to 3): (i) work with the team's partners funding agencies, industry, etc. - to establish the goals of the project and assess progress; (ii) advise the team's PhD students on their research related to the project's goals; and (iii) work with the team's graduate students to supervise undergraduate team members as they develop applications and experiments that utilize or test the team's research results.

- The PhD students (1 to 3): (i) pursue fundamental research related to the faculty member's field of research; and (ii) mentor the Masters students and undergraduates that are assisting with this research.

- Master's students (1 to 4): (i) assist the faculty members and the PhD students with their research; and (ii) serve as mentors to the undergraduate students as they explore and develop new applications based on the technology focus of the team.

- Undergraduates (8 to 15): Earn academic credit each semester, for up to seven semesters, for their work with the team's faculty, graduate students, and project partners to develop, deploy, and test new applications and systems.

- Project Partners: Provide support for and/or participate in the project. The partners may be organizations within Purdue, such as Purdue Intercollegiate Athletics, that host an application or may be funding agencies or companies that provide financial support for the team's research efforts.

The VIP program is supported by a track of three courses, one each at the sophomore, junior and senior levels. The following is the course description for the senior-level VIP course.

$===$ Begin Course Description $===$

\section{ECE 495V Senior Participation in Vertically Integrated Projects (VIP) in Electrical and Computer Engineering}

Variable Credit

This is a Special Content course. No more than 6 credits of Special Content type courses may apply towards the ECE Requirements of the BSEE. Excess hours can be used as Unrestricted Electives.

Experimental Course offered: Fall 2005

Prerequisites: Senior standing in Engineering

Corequisites: None.

Catalog Description: This course provides an opportunity for undergraduate students to explore and develop comprehensive applications of electrical and computer engineering technologies, especially as they relate to active research areas of Purdue faculty members. Students will learn 
about the underlying research, and will work on teams to formulate applications of the research that addresses real-world needs. Students will attend a weekly lecture that provides an introduction to a broad range of applicable technologies and development tools - some associated with the activities of specific teams, and some addressing topics of more general value to students enrolled in the course. These lectures will be drawn from a pool of 36 different lectures; so students can register for VIP courses as many as three times and still see new lecture material each semester. Together the VIP courses ECE 295V, ECE 395V, and ECE 495V in ECE create a vertical project track under which students work in multidisciplinary teams on long-term engineering projects. Each team consists of a mix of sophomores, juniors and seniors. Projects of at least one year in duration are intended to solve real problems that are defined in consultation with advisors who are Purdue faculty members, graduate students, or representatives of industry of the end-user population. Students are encouraged to participate in a VIP team for two or more semesters via enrollment in ECE 295V while a sophomore, ECE 395V while a junior, and ECE $495 \mathrm{~V}$ while a senior. Projects that serve customers from community service or educational organizations will be conducted within the EPICS framework rather than VIP.

\section{Required Text(s): None.}

Recommended Reference(s): None.

\section{Course Outcomes:}

A student who successfully fulfills the course requirements associated with at least 3 credits of VIP taken over 2 or more semesters will have demonstrated:

1. An ability to apply knowledge of communications, signal processing, and computer engineering to the design of applications solutions. $[1,2,3,4,5,7 ; \mathrm{a}, \mathrm{b}, \mathrm{c}, \mathrm{e}, \mathrm{I}, \mathrm{j}, \mathrm{k}]$

2. An understanding of design as a start-to-finish process. $[3,4,6,7 ; \mathrm{b}, \mathrm{c}, \mathrm{e}, \mathrm{f}, \mathrm{h}, \mathrm{k}]$

3. An awareness of the customer in engineering design and professional and ethical responsibility. [6,7;g,h,j]

4. An ability to function as part of a team and an appreciation for the contributions of other individuals on the team. $[6 ; \mathrm{d}, \mathrm{g}]$

5. An ability to communicate effectively with both technical and non-technical audiences. $[6 ; \mathrm{d}, \mathrm{g}]$

\section{Lecture Outline:}

Weeks 1-15: All students in VIP have one common lecture hour each week. During this hour, students will attend lectures that address a broad range of electrical and computer engineering technologies including topics that are relevant to the team projects and the development of applications based on these technologies. Lectures also address good design principles, project management, and project communications.

Lab Outline, by Week:

$1 \quad$ Major course milestones 
2 Team Organization and Semester Planning

3 Personal Semester Goals

$4 \quad$ Project Proposal (new projects); Project Demonstration (continuing projects)

$5 \quad$ Review of Design Notebooks

8 Peer Evaluation and Self assessment

$9 \quad$ Progress report

11 Midterm Project Review

15 Final Project Presentation, Team Report; Review of Design Notebooks; Peer Evaluation and Self Assessment

$===$ End Course Description $===$

\section{A Prototype VIP Team: The e-Stadium Team}

The Appendix provides description of several of the current VIP teams so the current breadth of coverage the program can be determined. In this section, we provide full details for one team, the e-Stadium project team. Full information about this project's deliverables and the team are available at http://estadium.purdue.edu and http://shay.ecn.purdue.edu/ estadium, respectively.

The e-Stadium VIP team has created two testbeds for research in wireless communication: a production testbed and a research testbed. These testbeds complement each other: the data gathered from the production testbed generates research questions that result in new solutions developed in the research testbed that are then deployed and tested in the stadium.

The production testbed is a "Living Lab" that enables the web-based delivery over wireless channels of "infotainment" to fans PDAs and smart-phones during home football games. This production testbed is supported by ITaP, the organization that manages the information technology infrastructure at Purdue. It has been instrumented by the e-Stadium team with custom software and wireless sniffers that enable the team to fully characterize how fans use the system, how network traffic behaves, and how the wireless channel affects the on-demand delivery of content -- especially multimedia content in the form of 1 to 2 minute long video clips of game highlights.

The research testbed provides an environment in which the graduate students and undergraduates test new concepts resulting from the graduate students' research efforts, develop new applications for the stadium, perform experiments, and explore new technologies.

This project has already resulted in two publications, one accepted and one in review, in technical conferences in the area of wireless networks and computer networks ${ }^{3,4}$. These publications describe the research and data gathered by graduate students and faculty associated with the project. The undergraduates have prototyped the web applications accessed by fans and have assisted with the gathering of data about the wireless channel. We expect many more publications to come from this large-scale engineering project over the coming semesters and years - with undergraduates appearing as co-authors on many of them. 


\section{The e-Stadium Vertically Integrated Projects (VIP) Team}

GOALS: To enhance football fans' game-day experience by enabling them to use their PDAs or smart-phones to access innovative infotainment content over a wireless data network deployed throughout Ross Ade Stadium and other athletic facilities at Purdue.

TECHNOLOGIES: Wireless networks, web applications, databases, graphics, video compression, and video delivery over wireless networks.

ACCOMPLISHMENTS/DELIVERABLES: Video replays, up-to-the-minute game statistics, play-by-play, food locations, hotel and restaurant info, and many other types of information are available on demand over the wireless network from fans' PDAs or smart-phones. Location discovery service, admission control strategies, and traffic logging capabilities were developed for wireless networks. Current projects include development of: additional infotainment applications, software tools for analyzing traffic wireless channels, and wireless sensor networks for new infotainment and safety applications.

RESEARCH ISSUES: Scalable delivery of video over wireless channels; design and optimization of wireless networks; design and applications of sensor networks; design of graphical user interfaces.

TEAM ADVISORS: Faculty Members - Ed Coyle (ECE) and Ron Glotzbach (CGT); Graduate Students - Xuan Zhong (PhD), Aaron Ault (MS).

SPONSORS: Cisco, Intel, Verizon

PROJECT PARTNERS: Center for Wireless Systems and Applications (CWSA), Information Technology at Purdue (ITaP), and Purdue Intercollegiate Athletics.

\section{DESIRED DISCIPLINES AND PREPARATION:}

EE - Background/interest in networking and wireless communication; General programming skills would be helpful but are not required

CmpE, CGT, CS - Background/interest in databases, web programming and/or graphics; Database experience would be helpful but is not required.

MANAGEMENT - Background/interest in marketing and commercialization is desired

FURTHER INFO: http://shay.ecn.purdue.edu/ estadium; http://estadium.purdue.edu

\section{Initial Course Evaluation Results and Conclusions}

In this section we provide a summary of student responses to an evaluation of the VIP program carried out at the end of the Fall Semester of 2005. The purpose of the evaluation was to determine how effectively the course was meeting the goals that have been established. At this 
point, 30 undergraduate students were enrolled in the program and 19 responded to the survey when it was distributed amongst the students attending the teams' final project presentations at the end of the semester.

\section{Question 1: What are the three most valuable non-technical things you have learned by being a member of a VIP Team?}

When asked, "What are the three most valuable non-technical things you have learned by being a member of a VIP team," the 19 VIP participants responded with sixty-one (61) authentic comments reflecting nineteen categories. Seventy-four percent, forty-five (45) of the sixty-one (61) comments, fell within the following seven categories and forty-four percent of these comments related to teamwork; a fundamental component to the VIP Program.

- Teamwork (20 Comments)

- Interpersonal Communication (6)

- Public Speaking and Related Skills (5)

- Personal Responsibility (4)

- Time Management (4)

- Problem Solving (3)

- Accessing Information (3)

The responses confirm a high level of value placed on the team-based curricular environment. In particular, the importance of coherence, distribution of labor based on skill sets, overcoming obstacles as a team, successful collaboration, and learning to work with differing styles and individuals from diverse backgrounds.

Interpersonal communication skills comprised $24 \%$ of comments within the top 7 categories, specifically the ability to effectively communicate one-on-one and as a presenter in front of a broad audience. The importance of "clear communication within a team" was also conveyed reinforcing the merit of a clear exchange of ideas, directions, and duties within teams.

Of great interest was the critical inclusion of personal responsibility as a compliment to teamwork. Students acknowledged taking initiative, being responsible, executing beyond expectations, and self-discipline as the most highly valued attributes of the VIP instructional setting. This finding is key and counters the limitations of team-based instruction often cited throughout the literature.

Only one of 61 comments emphasized the awareness of research and research techniques as a key value to the VIP experience. This finding falls short of one of the program's critical goals: to recognize the importance the role of research has in the design process and for graduate assistants and faculty members to model and promote research techniques via undergraduate instruction. It is clear that these techniques were indeed modeled (see responses to Question \#3) but not considered highly valued by the responders. A direct question probing the existence of the research component (\#3) improves on this finding but does not clarify why it is valued less so than other more common attributes. Further investigation is needed. 
Question 2: In two to three sentences, how has the "project-focused" approach to instruction aided in your improved understanding and application of the design process?

The premise of the VIP Program is to: build on the realities and expectations of a unique customer, over time, within an authentic educational design environment; absent of artificial simulations and exercises that could detract from the product's purpose and customer's goal. It is evident by the responses that this premise was comprehended by most of the participants. One responder noted, "It was challenging but it's great to know what the goal is at the end." Further, "It was fun seeing what we learned in a project class being used in a real world application and design." Another commented, "This is my only class in which I got to see an idea be done in reality."

The "reality" of the projects defines the instructional strategies operating within the VIP Program and its project teams. Responders stated that the "project-focused" approach enhanced their technical knowledge, advanced their problem solving skills, and enabled them to apply the design process. The importance of planning, task sequencing, resource gathering, and results oriented efforts were also stated.

One student summarized this finding well, "The project approach has allowed me to channel my efforts into some producible output and I have been able to learn more by "doing" than I would just sitting in a classroom and completing homework." A fellow participant expanded on the relevance this instructional approach had on understanding the design process, "The projectfocused approach has helped me to learn various stages of the design process and what it takes to move forward in each stage."

This recognition and the tangible outcomes that resulted support an authentic problem-focused learning environment.

Question 3: Part a -- Incorporating research goals into the design process is an attribute of VIP. List three research goals related to your project that you have become aware of during this semester. Part $b$-- How were these goals brought to the attention of your team? (*)

The existence of research within the undergraduate project-focused curriculum becomes evident in the responses to the above questions. Twenty-five (25) of the forty-six (46) research goals documented by participants applied the presence of research directly to the design process, product development, and implementation. The connection between the importance of research and the reliability of design decisions is a critical observation and a hallmark of the VIP Program and its instructional uniqueness.

Other recurring research goals included: technical knowledge and application, investigation and development of data transmission, comparison methods, conclusions, and results. When asked "how" they become aware of research goals, some undergraduate students stated standard means via the professor, the TA, etc. Yet, the most progressive conclusions were those goals developed through self-discovery:

- "When we came across obstacles we realized we need to research these areas more." 
- "When the conceptual idea was not being realized."

- "Though much of the semester was spent brain storming, we began to investigate the resources and knowledge necessary to accomplish this system."

Some participants recognized the necessity for research via their team goals and interactions:

- "The need to have these goals achieved pushed us to work hard on completing the tasks delegated."

- "With the discussion and guidance from the advisors, as well as discussion with team members."

- "For our sub-team to reach the goals, we needed to accomplish all these tasks."

The VIP instructional environment has provided the participants with suitable experiences to draw from their own knowledge-base and to determine further investigation that directs them to proper design decisions, quality products, timely delivery, and positive customer relations.

Question 4: Mentorship by faculty members, graduate students, and peers is central to the VIP Program. Please note below the degree to which you have directly benefited by the emphasis on mentorship.

The positive results that follow denote the centrality of faculty, graduate assistants, and team members supporting one another in the VIP learning experience. Is it possible for an instructional experience to promote technical and professional mastery, self discovery, team exploration, and knowledge in the absence of conventional academic competition and instruction? Where the end goals of the project and necessity to work as a team are primary to learning? Where mentorship provides strength and encouragement to students and positively affect instructional outcomes? Where professors' research interests and educational attributes are sustained? Further study into these questions would support not only the existence and quality of mentorship within VIP but the results of successful mentoring over time.

\begin{tabular}{lrccccc} 
& Greatly & \multicolumn{1}{l}{ Somewhat } & Unknown & Little & None \\
Faculty Mentorship (NR-2) & 14 & 3 & & & & \\
Graduate Assistant Mentorship (NR-2) & 9 & 3 & & 1 & 2 \\
Peer Mentorship (NR-2) & 10 & 5 & & 2 &
\end{tabular}

Question 5: Part a -- VIP offers a direct benefit (system, product, or service) to a real customer. List one thing above all others that you now know about customer relationships that you did not know before participating as a VIP team member. Part b -- How do you expect to incorporate this new customer knowledge in your future career?

The results of these questions focus on two important components of the VIP experience; the existence of a REAL customer and the important relationship a customer has with the engineer. The actualization that the customer is a partner throughout the design process is essential and reflected in the following statements:

"A product is only as successful as its ability to help the customer."

"The customer doesn't care about technical issues, it just has to work." 
"Product has to be fool-proof and can be used by anyone."

"Customer requests can change the project in no time."

This partnership guides the young engineer to other related and critical components necessary to achieve success as a professional. Incorporating customer knowledge into daily professional practices is understood by VIP participants. Nine categories (9) were identified to reinforce the worthiness of these practices.

- Product Quality

- Customer Design Considerations

- Product Planning and Delivery

- Problem Anticipation, Testing, and Resolution

- Relationships and Communication

- Seeking Assistance

- Design Considerations

- Selling Ideas

- Meeting Public Demand.

Students recognize that customer-based problem solving is fundamental. Comments include: "Think from the user's perspective." "Research deeply arising problems." "One could design the coolest and the most efficient product, but if it's not what the customer wants, it is of no use."

Of additional intrigue is the acknowledgement that asking for timely assistance contributes to personal success, product quality, and customer satisfaction. There should be no fear in seeking knowledge in an environment rich in support and guidance. The VIP Program reflects well this desire.

\section{References}

1. Website for the Vertically-Integrated Projects (VIP) Program: http://shay.ecn.purdue.edu/ vip .

2. E.J. Coyle, L.H. Jamieson, and W.C. Oakes, "EPICS: Engineering Projects in Community Service," International Journal of Engineering Education, Vol. 21, No. 1, pp. 139-150, January 2005.

3. X. Zhong, H.-H. Chan, T.-J. Rogers, C. Rosenberg, and E.J. Coyle, "The Development and eStadium Testbeds for the Research and Development of Wireless Services for Large-scale Sports Venues," Proceedings of the 2nd International IEEE/Create-Net Conference on Testbeds and Research Infrastructures for the Development of Networks and Communities, Barcelona, Spain, March 1-3, 2006.

4. X. Zhong, H.-H. Chan, T.-J. Rogers, C. Rosenberg, and E.J. Coyle, "The eStadium Testbed and Research Issues in the Delivery of Multimedia Content over Wireless Channels," Proceedings of the 25th Annual Joint Conference of the IEEE Computer and Communications Societies (INFOCOM 2006), Barcelona, Spain, April 21-25, 2006.

\section{Acknowledgements}

The VIP program grew out of the HP Mobility Projects program that was started by Professors Jan Allebach, Charlie Bouman, Ed Coyle, Ed Delp, Jim Krogmeier, and Catherine Rosenberg in 2001 with a grant from the Hewlett Packard Company. It was later incorporated into the Center for Wireless Systems and Applications (CWSA). 


\section{Appendix - Descriptions of VIP Teams for 2006}

Faculty in ECE have been encouraged to create VIP teams that support their research efforts. The results to date have been very encouraging, as can be seen from the team descriptions that appear below and on the following pages.

\section{The Multimedia Vertically Integrated Project (VIP) Team}

TEAM TITLE: Location-Aware Image Database

GOALS: To provide image-based navigation guide for mobile users. A user can take a picture of a nearby landmark and send the image to a server. The server identifies the image to decide where the user is located. A user can also input a starting location and a destination. The server will provide a customized virtual tour connecting these two locations.

TECHNOLOGIES: image processing, database, location-based service, wireless network

ACCOMPLISHMENTS/DELIVERABLES: This project started in fall 2003. Currently there are 600 images of Purdue campus and 12000 images of West Lafayette. Each image is annotated with location, time, and compass heading. Virtual tours can cover approximately $25 \%$ area of West Lafayette. Several pixel-based image comparison algorithms have been implemented.

RESEARCH ISSUES: image comparison algorithms, especially for outdoor landmarks. Location-based image search, scalability.

TEAM ADVISORS: Edward J. Delp and Yung-Hsiang Lu

SPONSORS: Intel

PROJECT PARTNERS: Purdue Center for Wireless Systems and Applications

DESIRED DISCIPLINES AND PREPARATION:

EE - digital signal processing, image processing $\mathrm{CE}, \mathrm{CS}$ - programming in C and Python, mySQL

MANAGEMENT - team management and communication

ADDITIONAL INFORMATION: http://shay.ecn.purdue.edu/ multimed 


\section{The Wireless Propagation Vertically Integrated Project (VIP) Team}

TEAM TITLE: Wireless Propagation

GOALS: To study urban and rural (indoor and outdoor) radio wave propagation by using stateof-the-art ray-tracing models and experimental techniques. This understanding will eventually lead to new and fast physics-based macromodels for novel radios (e.g. ultra-wide-band radio)

TECHNOLOGIES: Existing macromodels (e.g. Okumura Hatta), 3D fast ray-tracing simulator (EMTeranno) for wireless propagation (developed by EMAG Technologies Inc.), our robotic system for automated measurements.

ACCOMPLISHMENTS/DELIVERABLES: This will be a new VIP team, but its work will be leveraged by relevant research work already been completed by Prof. Peroulis' group. Initial goals will include: 1) review of existing channel models, 2) review of ray-tracing techniques, 3) usage of EMTeranno software tool, 4) conduct preliminary measurements.

RESEARCH ISSUES: The work from this team will help improve research-oriented ray-tracing techniques and will enable the development of new and fast macro-models for novel radio schemes (e.g. ultra-wide-band radio)

TEAM ADVISORS: Faculty - Dimitrios Peroulis; Graduate Student - Chih Wei Chang.

SPONSORS: EMAG Technologies Inc.

PROJECT PARTNERS: EMAG Technologies Inc.

DESIRED DISCIPLINES AND PREPARATION:

$\mathrm{EE}, \mathrm{CmpE}, \mathrm{CS}$ - Interest in radio wave propagation. Some (but not necessarily all team members) should have some exposure to electromagnetic fields and waves. No programming skills required (limited usage of MATLAB may be necessary).

ADDITIONAL INFORMATION: Please email Prof. Peroulis (dperouli@purdue.edu)

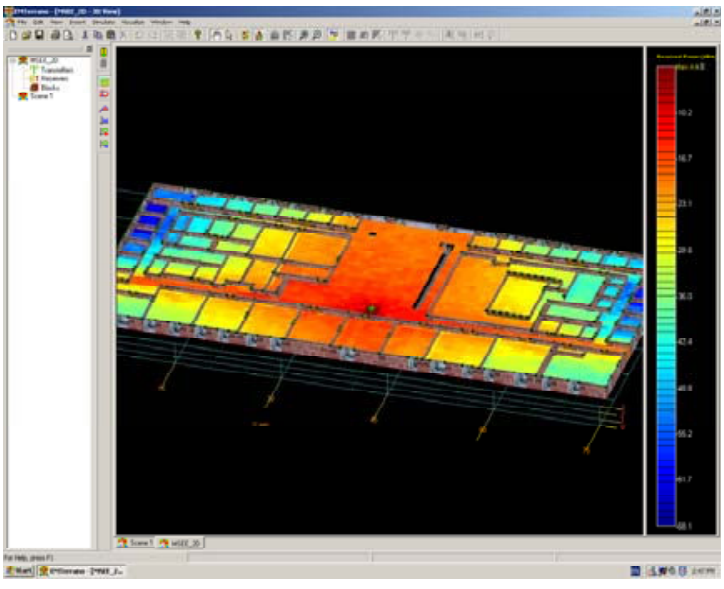

Example 1: Simulated wireless propagation in the second floor of the MSEE building.

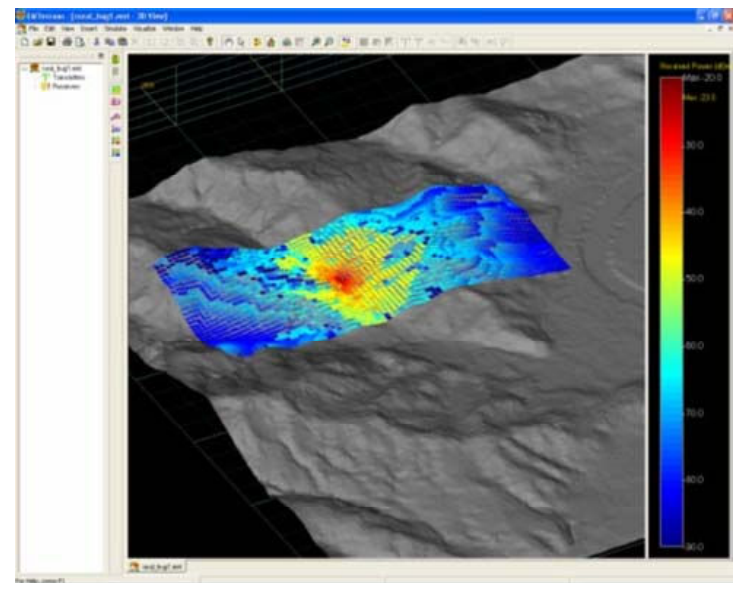

Example 2: Simulated wireless propagation in rural environment (from www.emagtech.com) 


\section{The Digital Publishing Vertically Integrated Project (VIP) Team}

\section{TEAM TITLE: Digital Publishing}

GOALS: To create systems, software tools, and knowledge bases to enable efficient management of multiple media information and repurposing for high-quality presentation in a variety of media and devices. Multiple media information may include text, images, 2D and 3D animations, audio, and video.

TECHNOLOGIES: Large format printers, photo-quality printers, high-speed digital presses, web-publishing, high-resolution displays, digital cameras, scanners, document models, object and page-layout models, databases.

ACCOMPLISHMENTS/DELIVERABLES: This VIP team started in Fall 2005. Initial goals are being defined, but include: development of an interactive agent to assist users of high-end digital publishing software; software tools to enable faculty to easily and rapidly generate courseware; and development of a content repository for the EPICS and VIP programs.

RESEARCH ISSUES: Monitoring and tracking a user's skill level and need for assistance with a software application; model the characteristics of good document design including layout, colors, and fonts to support automated document creation; search and retrieval of desired content from large databases; modeling and understanding output device capabilities and limitations as they relate to document creation.

TEAM ADVISORS: Faculty - Jan Allebach, Ed Coyle; Graduate Students - Xiaojun Feng, Mu Qiao, Ari Suwendi.

SPONSORS: Hewlett-Packard Co.

PROJECT PARTNERS: On Campus -- Professional Writing Program, Digital Learning Collaboratory, Agricultural Communications, Purdue Printing Services, EPICS, the Digital Publishing Laboratory in Discovery Park. Off Campus - PRISM (Initiative for Publishing Rich Information Sources in Multiple Media), HP

\section{DESIRED DISCIPLINES AND PREPARATION:}

EE - Background/interest in imaging, image processing, multimedia; Programming skills would be helpful but are not required.

CmpE, CGT, CS - Background/interest in databases, web programming, and/or graphics and print media. Experience in these areas would be helpful but is not required.

MANAGEMENT, CFS - Background/interest in marketing and commercialization is desired.

ADDITIONAL INFORMATION: http://shay.ecn.purdue.edu/ dpublish 


\title{
The E-Transportation Vertically Integrated Project (VIP) Team
}

\author{
TEAM TITLE: e-Transportation
}

GOALS: To create systems and software using advanced wireless communications and information technologies to improve the efficiency and safety of automotive, bicycle, and pedestrian transportation, and to build and test prototypes of these systems.

TECHNOLOGIES: Wireless networks, sensors, interface circuitry, GPS, GIS, databases, embedded digital systems, analog and digital data acquisition, signal processing, traffic signal control and sensing, and automotive systems (vehicle data bus, vehicle suspension system, vehicle safety systems).

ACCOMPLISHMENTS/DELIVERABLES: There are two e-Transportation projects:

- Modeling and measurement of inductive loop detection zones for bicycles. Models for detection of bicycles by inductive loop detectors have been developed and numerical determination of bicycle detection zones has been accomplished and verified using field measurement. Further work on this project will involve receiver operating curve characterization of inductive loop detection performance.

- Road smoothness estimation and pothole detection from ride acceleration measurements. A cargo van has been instrumented with GPS, axel and body mounted accelerometers, and a transmission rotation sensor. The collection of data from these sensors has been automated using an in-vehicle data acquisition system. Positiontagged vertical acceleration data has been processed via several algorithms for detection of pavement failures and the estimation of their locations. Further work on this project will involve improvements to the data acquisition system, the integration of additional vehicle sensors, and refinement of signal processing algorithms.

RESEARCH ISSUES: Signal processing, system identification, and fusion of data taken from a fleet of heterogeneous vehicles.

TEAM ADVISORS: Faculty - Darcy Bullock (Civil), James Krogmeier (ECE); Graduate students - Tarkesh Pande, Srinivas Vanjari.

SPONSORS: Motorola

PROJECT PARTNERS: Delphi Electronics and Safety (Kokomo, IN), Center for Wireless Systems and Applications, Joint Transportation Research Program, Indiana Department of Transportation.

DESIRED DISCIPLINES AND PREPARATION:

EE, ECET - Background/interest in signal processing; embedded systems; circuit design; networking and wireless communications. Programming skills would be helpful but are not required.

CE - Background/interest in transportation systems; traffic signal control; GIS.

ME - Background/interest in automotive systems; vibrations.

CmpE, CIT, CS - Background/interest in databases, web programming, and/or graphics; Database experience would be helpful but is not required.

MANAGEMENT - Background/interest in marketing and commercialization is Desired.

ADDITIONAL INFORMATION: http://shay.ecn.purdue.edu/ wtrans. 